Original Research Paper

\title{
Optimizing the Newspaper Distribution Scenarios using Genetic Algorithm: A Case Study of India
}

\author{
Sachin Suresh Kamble, Rakesh Raut and Shradha Ashok Gawankar \\ Operations Management, National Institute of Industrial Engineering (NITIE), India
}

Article history

Received: 13-04-2016

Revised: 25-02-2017

Accepted: 01-03-2017

Corresponding Author:

Sachin Suresh Kamble

Operations Management,

National Institute of Industrial

Engineering (NITIE), India

Email: sachinnitie06@gmail.com

\begin{abstract}
This paper attempts to optimize the various newspaper distribution scenario as observed in India. It found from the literature that earlier research work carried out in optimizing the vehicle routing networks problem using time window and scope was limited to distribution from newspaper printing location to the vendor point of distribution. This paper focuses on the distribution of newspaper from vendor to the newspaper reader/customer. In this study case study method is used and the circulation activity is modelled with different field scenarios with a aim of minimizing the overall (total) delivery time of the Newspaper. The major aim of this paper was to identify the issues, while distributing the newspaper by the vendor at the hub to the end reader. The company under consideration had an objective of finishing the last newspaper delivery by 6:30 am. To optimize the same the paper identified the following scenario:
\end{abstract}

Case 1. Delivery to Independent Houses Located in a Community

Case 2. Delivery to an Apartment Cluster

Case 3. Delivery considering the various modes of transportation

The present paper optimized the same using genetic algorithm as the optimizing tool. The model with different scenarios presented in the paper will help the newspaper distribution planners to understand the various issues on the field and achieve to have a successful distribution strategy within the set objective of reaching the last copy of newspaper by 6:30 am to the reader. This will help not only the newspaper company under consideration but the entire newspaper industry. This paper contributes to body of knowledge of newspaper industry its major research implications are 1. It provide insights for a particular type of functioning environment, where speed and time play an critical role. 2 . In certain type the time delays in the distribution network will impact the consumer's preference which will lead to improved market share and more satisfied customers.

Keywords: Time Window, Genetic Algorithm, Distribution Process, Indian Newspaper Industry

\section{Introduction}

The Indian newspaper industry is one of the largest in the world. Newspapers were once the lifeline of the nation and was hailed as the fourth estate for its sheer power in forming public opinion and creating revolution on many issues. The press in India is strong, sturdy and very effective. India press is oldest industry it has renowned track record evolved over 200 years, study conducted (Narasimhan and Ramana, 1995) shows the pioneer importance of press in India, it is most reputed and respected sector because of its professional excellence, commitment and ethics towards democratic values and practices. Sutar (2007) study highlighted newspapers industry as most effective which high impact source of information covering current information which helping in the social reformation it keeps the reader up to date by providing information, newspapers acquaint the reader with current affairs with that it has high impact on education system which in turn create awareness among people regarding their rights and freedom. The total number 
of newspapers and periodicals published in India was 51,960 in 2001. There were 5,638 dailies, 348 tri/biweeklies, 18,582 weeklies, 6,881 fortnightlies, 14,634 monthlies, 3,634 quarterlies, 469 annuals and 1,774 of other periodicity (Burger, 2013).

India is the ranked among top largest consumer in world of newspapers. Survey from World Association of Newspapers shows that the daily circulation of newspaper in India is more than 329 million in 2016. It is reported that in India one in every five daily newspapers is published when compared to world. Indian print media contributes to $45 \%$ of total advertising world, In India local newspaper is commonly read and very impactful in society. From last four five years, advertising and promoting in print media has been increased at a compounded annual growth interest rate of above $8 \%$. About $90 \%$ newspaper readers in India prefer news in both Hindi and other regional languages. Every few prefer to read newspaper online for numerous reasons for instance technical issue, unavailability in regional languages act as hindering factor in growth of online readership.

The reason behind the regional languages popularity is the number of reader population, which is why newspaper is not much affected by online reading in India, compare to rest of the world. There are two other reasons that covers Indian newspaper industry against the increasing numbers digital print.

First, the rate of newspapers in India are priced very low compare to other countries. English dailies are less being in circulations for years and priced higher with limited pages compared to regional and Hindi titles. As the competition has become extensive, regional newspaper prices further decreased. On the other hand, online reading was 'free', the content is free but reader has to pay for connection and access. The access to news, information, current affairs and features is cheaper mode to consume news in written form; a daily newspaper subscription may cost Rs. 100 to 150 per month. Newspaper can be shared but it is not possible to share your screen.

One of the important aspects of newspaper is logistics, which consist of dropping newspaper at a reader's home before sunrise. This kind of opportunity is unavailable at many places in the developed countries; the main reason is the labor cost of delivering the title is high-priced. In India, the abundance of job scarcity leads to work force, but the hawker gets a share of a cover price that is low.

However, as time had passed with the advent of digital technology, questions are ripe that whether print media can survive this onslaught (Das and Sengupta, 2013). The newspaper industry, these days are facing numerous challenges in the form of competition. The newspaper companies have to maintain the quality of the content, satisfy their customers and be competitive to its counterparts. One possible way to sustain the competition is reduction of the operational costs. Apart from the human resources, materials and machinery utilized in the manufacturing of the newspaper, the physical distribution of the newspapers to the customers contribute significantly for the operational cost associated with the newspaper publishing business heterogeneous newspapers ness. In addition, the major goal of the newspapers is to take the news to the customers the earliest. Therefore, the sooner newspaper reaches the customers, the more it will be capable of resisting competition.

The print media was successful to contribute (94.4\%) of its total revenues from the newspaper group. The magazine segments worth INR14 billion magazine faced many difficulties this year. Growth in the last year was because of increase in featured advertisement and number of circulation revenues. The main reason for advertisement revenue improvement were number of subscription and yield growth. In year, 2013 newspaper circulation increases the revenues by $8.1 \%$ year compared to last year, which was $7.3 \%$ in 2012 . The important reasons for achieving this increased growth rate was an increment in cover prices and introducing new editions. In metros and tier I cities the cover prices was increased by the publishers have because of the mature markets. Market value in comparison to the total industry growth, regional newspaper and other vernacular markets contributed exceptionally well even though there is low media saturation, increasing population and rising income level and access to education lead to growth in literacy levels. The success of overall print industry was largely contributed by Hindi dallies and the regional print newspapers. The Hindi newspaper subscription contributes to $10.5 \%$ to market which seen growth from INR68 billion in 2012 to INR75 billion in 2013 and regional newspaper add to $10 \%$ from INR69 billion in 2012 to INR76 billion in 2013 to overall market. The drop in Indian print media isn't as evident as it is in the developed countries, because the readership of English newspaper from print to digital media are experiencing growth in addition the increasing advertising pressure act as threat in coming years. In year 2013, print circulation revenue experience growth of $8.1 \%$, which is slightly on the upper side compare to the growth in the circulation revenue in year 2012 which contributed to $7.3 \%$ (Kumar and Sarma, 2015).

The evolution of this industry begins with print media in 1780s followed by radio in 1930s and later television into India. The digitalization of this industry commenced in early 1990s. India has an average accessibility to electronic media and among this $93 \%$ is entertainment audience and only $7 \%$ are news followers. India has 875.48 million (as of October 2013) mobile phone connections and 165 million Internet connections (as of 
March 2013) internet users. In India, the growth of new newspaper published across all editions of newspapers will be around $6 \%$ every year. This growth rate is more evident in the regional editions, which is the highest circulated daily in India with very strong brand recognition. Though the $24 \times 7$ news channels on television had its impact on the circulation numbers of newspapers, it is evident that India still 'wakes-up' with a cup of tea and the newspaper (Srivastava and Srivastava, 2015).

\section{Growth of Newspaper Industry}

The Indian print industry sustained steady position in 2014 with most players reinforcing their contribution in the existing print markets and combining their existing operations for better efficiency. The organization of the Indian print industry is divided into national and regional players. Indian newspapers market is big and dynamic in nature. In few years only since 2005, Indian newspaper industry has seen enormous growth.

Newspapers continued to contribute a major portion in the total revenues generated by the print industry in India as shown in Fig. 1 and 2. Worldwide news content and delivery pattern have emerged in the newspaper industry and these changes in newspapers and magazine subscription are establishing updated media channels which is in need of additional distribution network for future development. Survey indicate done till 31st March 2014, all the registered publications collectively contributed at 99,660, where dailies contributed to 13,350 and periodicals contributed to 86,310 of the total registered newspaper and magazines publications in India, out of which regional Hindi subscription added to over $40 \%$ and nearly $47 \%$ was contributed by the bilingual and multilingual publications.

\section{Revenue Contribution from Newspapers and Magazines}

Newspapers is one of the major contributor of revenue to the print sector. In year 2014, the contribution of newspapers to the total print industry revenue was close to $95 \%$. Out of all category magazines category continued to add just $5 \%$ of share of the total revenue of print industry. Some popular general interest magazines recorded a tiny growth; comparatively the niche magazines are holding strong position among both readers and advertisers. After identifying the importance of digital media, many magazine groups introduced electronic versions of their magazines edition in form of a mobile app or e-magazines. Few magazines stopped printing the physical copy entirely. With the increase of language dailies, the contribution from magazine in the overall revenue of print media is expected to drop down in the coming years.

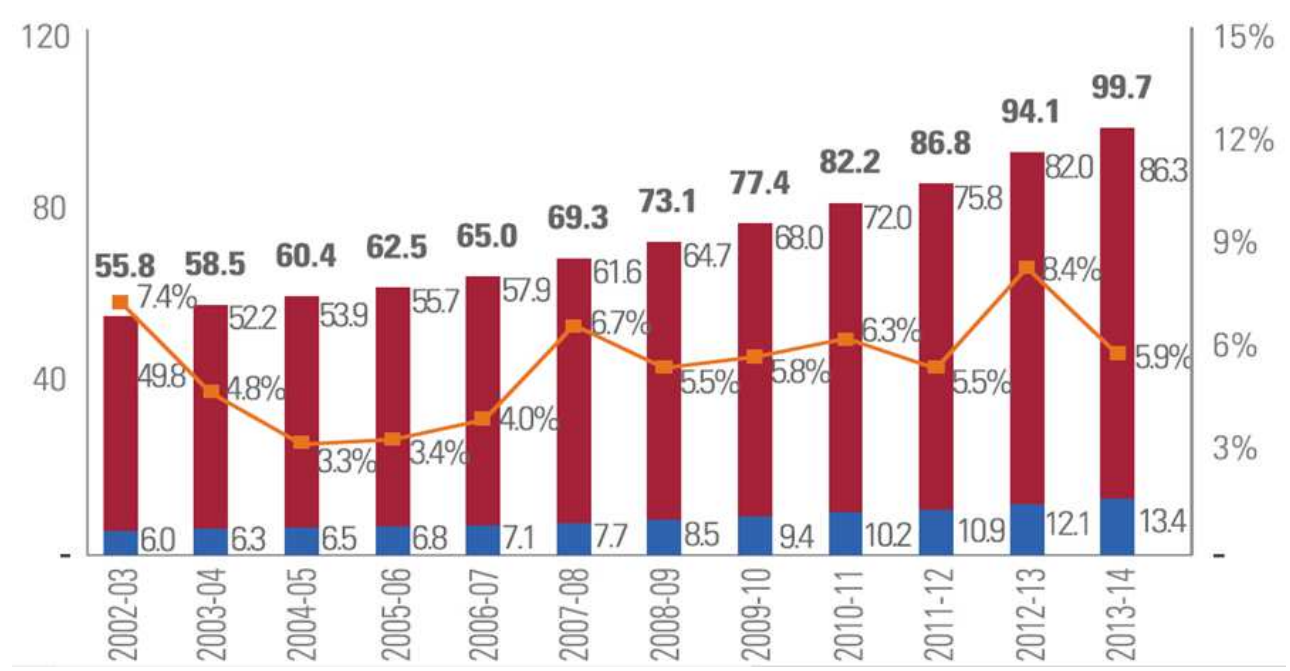

Fig. 1. Details of Registered newspapers and periodical (in 000')

\begin{tabular}{lcccccccc}
\hline Revenue contribution & 2012 & 2013 & 2014 & 2015P & 2016P & 2017P & 2018P & 2019P \\
\hline Newspaper industry & $94.2 \%$ & $94.4 \%$ & $94.6 \%$ & $95.0 \%$ & $95.4 \%$ & $95.8 \%$ & $96.2 \%$ & $96.4 \%$ \\
\hline Magazine industry & $5.8 \%$ & $5.6 \%$ & $5.4 \%$ & $5.1 \%$ & $4.6 \%$ & $4.2 \%$ & $3.9 \%$ & $3.6 \%$ \\
\hline
\end{tabular}

Fig. 2. Revenue contribution from newspapers and magazines 


\section{Challenges Facing Newspapers}

Incurrent scenario newspaper agencies functions in one of the most unpredictable environments any industry has faced in last 100 years. Since 1950 newspaper circulation in India witnessing decline, as consumer's preference changed they are more relying on television and social media, increasing advertising revenue compensated for this decline and helped newspaper industry to grow continuously. During 1950 and 2000, revenue generated by advertising in India reached to $300 \%$ growth. However, the growth of the internet and digital/social media in the last 15 years has transformed the picture of Indian newspaper industry, from 2000 onwards sales newspaper and advertising has fallen down in India.

The decrease in advertising revenue has covered the decline in newspaper circulation, but from year 2000 the revenues generated from advertising also dropped in India as the advertisers now prefer the latest media and personalized marketing strategies; this new trend contributed to $75 \%$ on total spending on advertising. In countries like India the revenue generated from advertising play vital role in overall development, with internet connectivity up gradation advertisers can follow trends in India.

The growth of print media provided opportunity to advertisers to personalize their messages and target audiences in market. However, the challenge not just limits to revenue generation for news media it is that news organizations' responsibility to access to news information under different situations and treat. It is the media decision with respect to the news authenticity; social media has given powers to the users to spread the news and to circulated information and photos, events details on the internet platform.

In addition, social media is also disrupting the news industry by giving control to the consumers to change their choice of preferences. Newspapers industry play a role of aggregators by relating common news with coverage of sport tournament, business collaborations, entertainment etc. Which leads to the aggregating role taken over by social media services such as Yahoo and Google. The profits contributed by news on social media platform lime Google, Facebook, Yahoo etc could match up the reduction in revenues of newspapers. However, in the near future the major challenge faced by the combined news data is the source of contents, analytical and investigative journalism and authenticity of news in particular.

Many newspapers identified the potential strength of the internet; many added various innovative idea that lead to tremendous success in future. With this changes many print media are reaching more readers compare to before online, they have struggled to monetize these readers. For newspaper industry if $15 \%$ of revenue comes from digital products, its performance is consider as best; few of the newspaper agency receive more than $20 \%$ of their revenue from digital products, advertisement etc. It clearly visible that revenues generated from subscriptions and advertising, in addition to recent print revenues, will not come from print revenues. It is a known fact that news agencies are competing for advertising with increasing number and popularity of digital news and information providers.

Newspaper owned industries, need most excellently integrate the production, loading and advertising products supplement distribution system that is holistic in nature and it as promotion strategy. The difficulty is not restricted to technology and equipment, it adds in having the capability to adapt the newspaper's processes in production and distribution with the logistics information to make it more flexible, competent, resourceful and customer-oriented operation. Successful newspapers agency understands that core operations of their flourishing business is their distribution and logistics network and that it is important to identify the areas performance that can be improved in order to have competitive advantage. The newspaper publishing can be broadly classified as production and distribution. The production processes involved are highly optimized by the implementation advanced technology and machinery. One of the major scope for reducing the operational cost is the optimization of the distribution process. The distribution process contains two segments, transportation from press to a common distribution center or hub and distribution of papers from the hub to the house of customers.

The process of distribution of the newspaper is dependent on various factors like the demand, size of newspaper and their supplement, zones and distribution dates, distribution rates, mode of transportation, time of reach of newspaper to the customers etc. In addition, the distribution of the newspaper should be achieved with minimum cost. This paper attempts to study the distribution aspects of newspaper.

\section{Review of Literature}

Almost every industry required to understand how suggested new changes will affect the overall business. Industry need to evolve different strategies to tackle with these modifications to guarantee the continuity of survival in the market. Indian newspaper industry is one of the few industries in the world that is showing a tremendous growth. However, at same time the consumer's attention and time spent is dividing among the various available media options to them to access the information and enjoy entertainment. 


\section{Synchronizing Production and Distribution of Heterogeneous Newspapers}

In the literature the problem of coordinating production and distribution of heterogeneous newspapers is studied by various authors (Russell et al., 2008; Bohnlein et al., 2009; Buer Van et al., 1999; Dawande et al., 2006; Geismar et al., 2008; Akkerman et al., 2010; Huo et al., 2010; Geismar et al., 2011; Cakici et al., 2012) as well as a few authors have studied only the distribution aspects of the newspaper. Garcia et al. (1999) developed a simulation model with an objective of improving the newspaper printing, packaging and distribution processes. Russell et al. (2008) study tested the two-level and three-level supply chains for a medium size US newspaper agency in the Midwest region that delivers newspaper to households and businesses over 200 zip codes that spread across different states. The problem was defined as an integrated newspaper production and distribution supply chain management problem. Ullrich (2011) focused on integrating the production and outbound distribution scheduling in order to minimize the total tardiness. The overall problem consisted of two sub-problems. The first problem addressed the assigning of jobs on parallel machines considering the machine-dependent ready times. The second problem aimed on the distribution of completed jobs with a fleet of vehicles, which assumed to differ in the loading capabilities and ready times. Job-dependent completion times, distribution time windows, service times and final destinations were taken into account. Bohnlein et al. (2009) observes that the organization of production system and distribution network is becoming increasingly critical aspect in order to reduce the costs and to increase customer satisfaction. In this case if transportation plan its schedules closely connected with production plan schedules, similarly in the newspaper industry as it is done in perishable goods distribution which is immediately after production of goods.

\section{Vehicle Routing Problems}

Bohnlein et al. (2009; Chiang et al., 2009) identified that the majority of the newspaper distribution problem considers the dimensions of Vehicle Routing Problem (VRP). The standard VRP consists of vehicles that originate from sauce and return from destination to a single center that must cover each customer or node in the distribution network from the depot in one attempt as per the designed tours or routes that do not go beyond the vehicle capacity. The other variants of VRP problems identified in the literature are the Stochastic Vehicle Routing Problem (SVRP), Vehicle Routing Problem with Time Windows (VRPTW), Open Vehicle Routing Problem (OVRP) and other related methodologies. The popularity of VRP was attributed to the fact that VRP is a hard combinatorial optimization problem and addresses larger real-world problems more efficiently. VRPTW extends the formulation by adding the constraint that each customer or node must be serviced within a predefined time window. OVRP deals with the situations where the vehicles are not required to return to the depot after the last delivery or route completion. Gribkovskaia et al. (2008) have address the issue related to a single vehicle routing problem with mandatory deliveries and very particular and selective pickups, in which it is required to cover all deliveries, but pickups kept optional depending upon the revenue generated with each pickup. Nevertheless, it's compulsory to pickups and transported it to the desired depot. Wang and Chan (2013) research studied flexible delivery options and selective pickup problem using the time windows in which all the pickups are delivered to the same depots with required location and one reader is visited exactly once by one vehicle for one service. Yu and Dong (2013) studies a backhaul vehicle routing and delivery-scheduling problem with the objective of increasing the total business revenue that the vehicle creates during its backhaul trip. The problem has two constraints: The time constraint for the entire backhaul trip and the capacity constraint of the vehicle. Archetti et al. (2013) this study reports the problem of finding an efficient distribution plan to deliver free newspapers from a printing press (production plant) to various commute options like subway, bus, or train stations. The objective of this study is to group two factors: First, the free newspaper producing agencies wants to decrease the number of vehicle trips required to deliver all newspapers produced at the printing press (production plant). Second, the agencies is fascinated in decreasing the time required to deliver all newspapers, i.e., the time required to distribute all newspapers to the final readers. Ting and Liao (2013) suggested a unique problem formulation of particular pickup and delivery issues, which reduces the need for visiting all pickup nodes in the distribution network and examines a minimum-cost route for a vehicle with capacity constraint. The problem dealt in this study falls into the category of Delivery Problems (DP), in which the focus is not on the production of the newspaper nor the vehicle routing problem or route optimization. The problem focuses on the delivery boys picking the newspaper from the vehicle drop point, sorting them as per their route delivery plan and distributing them to the end readers. Unlike the problem dealt in this study, many researchers have focused on the Pickup and Delivery (PDP) problems that dealt with vehicles start from one depot, pickup and deliver all products and then return to the same depot. However, we find that the final delivery by the delivery boys to the reader's home has not received much attention in the past including the studies conducted by Min (1989; Mosheiov, 1994; Nagy and Salhi, 1998; 2005; Salhi and 
Nagy, 1999; Gendreau et al., 1999; Dethloff, 2001; 2002; Montane and Galvao, 2002; 2006; Süral and Bookbinder, 2003; Wasner and Zäphel, 2004; Halskausr et al., 2007; Hoff et al., 2009; Wang and Chen, 2013) have focused up to the drop points of the vehicles and their route optimizations. However, the aim of the problem is to find maximum customer coverage and optimal delivery consistency. Hernández-Pérez and Salazar-González (2009) studied the multi-commodity one-to-one pickupand-delivery traveling salesman problem in which the demand and the cost for delivering different commodities are known and the vehicle has a limited capacity. Each customer must be visited exactly once and the objective is to minimize the total cost.

Table 1. Chronological literature review

Author (s) Year Abstract

Sivaramkumar et al. 2015 The study consider multi-objective vehicle routing problem with time windows in terms of a decreasing total distance travelled by all vehicles in the given route, the total number of vehicles used (management beneficial objectives), the total gap between ready time and issuing time (customer beneficial objective). An improved genetic algorithm, called the fitness aggregated genetic algorithm, was implemented to resolve the problem. The proposed algorithm incorporates a fitness aggregation approach and dedicated operators, such as selection based on aggregate fitness value and best cost route crossover, to resolve the multi-objective problem. The algorithm was validated on Solomon's bi-objective benchmark models for the minimization of the total distance travelled and total number of vehicles used and the results formed by proposed algorithm are competitive to best-known results. After validating the proposed algorithm on bi-objective models, the third objective - namely, the total time gap between ready time and issuing time - is included in the bi-objective model. The results show that the suggested algorithm creates improved customer-satisfied routes without drastically affecting the total distance travelled and total number of vehicles used.

Ehmke et al.

2015 They proposed approach for preparing time distributions, which were used to create a feasibility check that can be "plugged" into any algorithm for the VRPTW and thus be used to solve large problems quickly. Their computational experiments show how the solutions change for some well-known data sets across different levels of customer service, two travel time distributions and several parameter settings.

Nguyen et al.

2014 The study present different population-based hybrid meta-heuristic for the periodic vehicle routing issue using time windows. This meta-heuristic is basically generational genetic algorithm that utilizes two neighborhood-based meta-heuristics to improve offspring. In the proposed method, neighborhood-based meta-heuristics are used for their capacity to escape local optima and deliver optimized and diversified solutions to the population of the next generation. Furthermore, the search performed by the neighborhood-based meta-heuristics repairs most of the constraint violations that naturally occur after the application of the crossover operators. The results are outcome of many numerical experiments and comparative analysis with different methods suggested in the literature review which indicate that recommended methodology is highly competitive, in nature and provides best solutions for a number of large scenario.

Wassan and Nagy

2014 The study examines new extensions to the vehicle routing issues. Different problem are combined in this study old, recent are considered placed in a taxonomy. A main objective of the study is based on assumptions usually made in the literature review and got lots of advantage for not making assumptions as constraints. This study uses Integer Linear Programming (ILP) formulation. It's highlighted that how formulation can be adapted to cater for different problem versions. This study argues that different solution methods covering meta-heuristics which provides solution to different models and what extra required for vehicle routing problem

Vidal et al.

2013 The study uses an effective Hybrid Genetic Search with Advanced Diversity Control for a large amount of group for vehicle routing problem using time-constrained, this article contribute distinct features to control the temporal dimension. Authors proposed new move evaluation techniques, using time window and duration constraints accounting will penalized infeasible solutions, this in turn allows evaluating moves from any conventional neighborhood based on arc or node interactions in amortized constant period. This study contributes to geometric and structural problem decompositions that established to cover large problems more efficiently. The proposed algorithm contributes to all existing state-of-the-art approaches on established literature benchmark by combining periodic, multi-depot, site-dependent and durationconstrained vehicle routing problem with time windows.

Russell

2013 This study uses a constraint programming approach with a modeling language and CP optimizer to support in the synchronization of the production operations and distribution (on time delivery) of multi-product newspapers to different locations. The objective function was distribution problem, which was formulated as an open vehicle routing problem with time windows and zoning constraints. The approach is applied to the newspaper production and distribution operations problem in a major urban area. 
Table 1. Continue

Archetti et al.

Burger

Wallace

Derbel et al.

Böhnlein et al.

Chiang et al.

Beatrice and Hanshar
2013 This article addresses the issue of finding an efficient distribution strategy to deliver free newspapers from a printing press (production plant) to commutate or used like subway, bus, or local train's stations etc. The objective of this article is to combine two factors: A. the free newspaper printing company wants to reduce the number of vehicle trips required for delivery of all newspapers produced at the printing press and $b$. the company is concerned in reducing the time required to sale all newspapers, i.e., the overall time take to get all the newspapers delivered to the consumers. Author's uses computational tests using real world data, result of the study highlighted that hybrid method is the best option in various problem settings in newspaper industry

2013 This paper aims to investigate the role of logistics in newspaper and magazine delivery routes, to find how they can be optimized. The results should assist media companies to cut the cost of logistics and to have a more effective delivery system. By using the Vehicle Routing Method, this study aims to develop a universal algorithm to apply to the routes currently used by Media 24 in Gauteng. Once the algorithm is created, a feasibility study will be performed to indicate how to program the problem. It will improve the efficiency of the delivery process. This may make a significant difference in not only the media company's logistics costs, but also in their unit costs, thus earning a greater profit for each copy sold.

2012 This study address the issues of finding distribution feasible routes from the distribution centre located in Kumasi along with its twenty-seven district capitals located in Ashanti region for Graphic Communication Group Limited (GCGL) office in the identified location, research objectives ensure timely delivery and cost-effective newspaper service. The objective problem was to formulate as Capacitated Vehicle Routing Problem with Time Window (CVRPTW) constraints by using Clark and Wright's Savings algorithm to design the solution for the identified problem. The algorithm takes in account the travel time matrix as input and continues to find the travel time savings between all the identified districts of the region. The identified problem was solved using VRP SOLVER computer program. The outcomes of the program provides comparison of results in terms of the total traveling time acquired by the Clarke and Wright savings algorithm and the actual distribution routes retained by company indicates that the current total travelling time can be further decreased up to $21.9 \%$.

2012 This research contributes to location routing problem with multiple capacitated centers and one incapacitated vehicle per center. Authors attempted new approach to make location and routing decisions simultaneous and efficient. In this research authors combined Genetic Algorithm (GA) with an Iterative Local Search (ILS). The reason to combine the hybridization is to increase the feasibility of the solutions generated by the GA using an ILS to increase the search space. The outcome of numerical experiments show that the hybrid algorithm improves the routing decisions, the outcomes is the best-known solutions obtained by the tabu search heuristic.

2011 This study address unique type of vehicle routing problem of one of the largest German newspaper companies, in the paper combines the vehicle routing problem with time windows and cluster-dependent tour starts (VRPTWCD). The objective of this research is to understand the varying print needs and post-printing schedules because unknown editorial constraints lead to the need for an active online control of the newspaper production, printing and distribution process system. The outcomes of this is an outlined dynamic transport problem which solved the online under consideration of unexpected alternation in production schedules. The solution perception is based on a multi-agent system consisting both several edition and vehicle agents. This solution can be applied to a real life application.

2009 This study test two-level and three-level supply chains for a midsize US newspaper agencies in the Midwest region that delivers newspapers to households and businesses covering more than 200 zip codes that spread across the various states. The problem is defined as an integrated newspaper production, printing and distribution supply chain management problem. By grouping model formulation, simulation and an improvement heuristic authors address both the efficiency and robustness issue in the solution by estimating the impact of the stochastic modelling and its nature on various parameters in both newspaper production and distribution system.

2009 This study propose use of genetic algorithms approach for MDVRP. The outcome of the study in the form of GA employs an indirect encoding and inter-depot mutation exchange strategy ready to adapt for the MDVRP with capacity and route-length constraints. The algorithm is analyzed on a set of 23 standard MDVRP problems from customers ranging between 50 to 360 . The results of computational analysis highlighted that the approach is competitive in nature with the existing GA. The outcomes improves the solution quality by comparing the GA's approach with other non-GA approaches, the results indicates that GAs are competitive in nature for the MDVRP, which leads to more room for future research on GAs for MDVRP, compared to Tabu search. 
Table 1. Continue

Russell et al.

Rajmohan and Shahabudeen

Lei et al.

Brown and Sumichrast

Carter and Ragsdale

Buer Van et al.
2008 Study uses tabu search meta heuristic to support the coordination and synchronization of the production and delivery of multi-product newspapers to majority delivery locations. The problem is formulated as an open vehicle routing problem with time windows and zoning constraints. The approach is applied to the newspaper production and distribution problem in a major urban area. Computational results indicates significant improvement in the production and delivery compare to an existing newspaper agency's operations.

2008 In this study, Genetic Algorithm (GA) based heuristic is proposed to solve Vehicle Routing Problem with Time Windows. The initial population of the GA is generated using Greedy Randomized Adaptive Search Procedure. The proposed algorithm is tested with bench mark instances and is found to be better solutions than published results.

2006 The study involves the integrated Production, Inventory and Distribution Routing Problem (PIDRP) which consider heterogeneous transporters with non-instantaneous traveling times and numerous customer demand depots with inventory capacity. The study contributes a two-phase solution method to this identified issue. In phase I mixed-integer program is solved which involves all the restrictions associated in the original model but with the transporter routings being constrained to direct shipments between facilities location and customer demand depots. The resulting feasible solution obtained from the phase I is always optimal to the original model. In the Phase II associated consolidation problem is solved to control the probable inefficiency involved in the direct shipment. The distribution consolidation issue is formulated as a capacitated transportation problem with additional restrictions and using solved heuristic approach. The result of this study is the performance of the contributed two-phase approach and report on its application to a real-life supply network.

2005 This study contributes empirical tests of the performance of GA and GGA consisting three aspects substantial, practical and importance, many authors considered this subject and contributed in the academic research. The objective of this article is torecordreal-world differences between a standard off-the-shelf GA and a tailored GGA. Based on the level of solution quality desired, it may be the required extra time and resources to design a tailored GGA. The improvement in solution quality may not be justified.

2002 This study contributes spreadsheet model developed to signify the pre-printed supplement insert scheduling problem using case study method of a medium-size newspaper agency. Using two commercial genetic algorithm (GA) performance of the optimizers is compared in this case study. The result of computational testing shows the GAs improve schedules that significantly decrease the post-press production department's insert processing time.

1999 This paper discuss a problem of production and distribution from the newspaper industry. Authors highlights the problem and use mathematical formulation technique, using heuristic search algorithms as strategy to develop solution for the problem. The data was collected from the newspaper agency and extensive data analysis was carried using computational experiments, the results indicates that re-using the same trucks which have completed previous routes help the newspaper industry to achieve low-cost solutions. Authors also tried to compare and contrast various heuristic search algorithms for optimal solution.
It is evident from the literature review that most of the studies focused on the aspects of newspaper production and distribution, with newspaper distribution getting more attention. The review further highlights that most of the studies in distribution covered the vehicle routing problems from the printing location to the point of distribution. In recent years there, models were tested with the time windows restrictions and the routes or the vehicles were optimized for maximum cost. However it is perceived that in India the newspaper deliver and distribution is controlled by highly unorganized method. The process of newspaper distribution in India follows a sequence firstly the paper packages are dropped by the vehicles at the sorting hubs (depots), the entire process is managed by newspaper vendor and dispatched to a variety of distribution locations. This paper aims on the various distribution network options the vendors employs at the field. The next section gives the detailed newspaper distribution process in India followed by the model development.

\section{The Newspaper Distribution Process}

In India, most of the newspaper companies follow a specific channel of distribution of circulation from the respected depots to the specific area with the subscribed publication. The broad process flow is as shown in Fig. 3. 


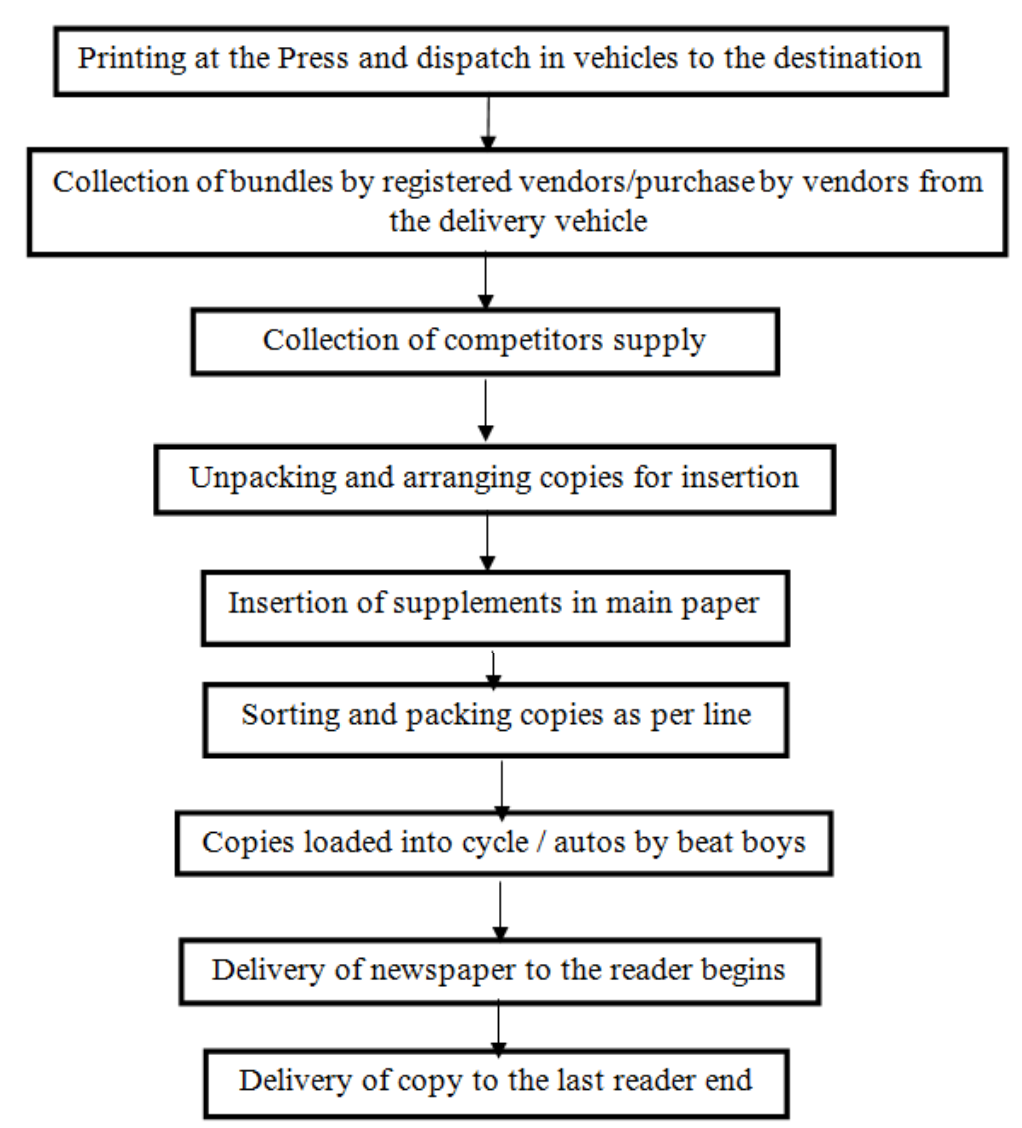

Fig. 3. Newspaper distribution process

\section{Printing}

The agents who control with the distribution network of daily newspapers update about number of papers required from the next day's demand by evening to the circulation department the newspaper agency. Resultant the requirement of newspapers is revised on a regular basis. However, there are not much variations in their daily requirements unless until some new customers are added or discontinued. The companies also print few extra copies of their paper, taking into account the fluctuations in demand, or to take care of any unexpected situations such as loss of packets, counting mistakes while packaging or theft.

\section{Packaging and Loading in Vehicles}

This involves the process of counting, packing, loading in vehicles and issue of challan to the truck/tempo drivers. The counting and packing processes at the press are done automatically while the loading activity is manual.

The vehicles which transfer the newspapers to the centres (depots) have a yearly agreement with the newspaper agency. The number of vehicles carrying these newspapers depend upon the number of newspapers demanded by the depot and the total distance of centres (depots) from the press to required destination. However, before the vehicle leaves the production plant other essential formalities such as distribution of challan and gate pass are completed. Challans or receipts are issued at the press in the name of the vendor and collected by the truck/tempo driver.

Once the vehicle leaves the printing press for the depot, the newspaper completes one half of the journey. But the critical part of the circulation process starts from here.

\section{Depot Activities}

This is the second half and the most difficult half of the journey of a newspaper. The circulation of newspapers from the depots to the readers is entirely performed by the vendors. The depot and the drop points is the actual site of action and the role of the newspaper Company remains only of selling and supervision from this stage onwards. The entire set of activities are performed by the vendor and his team that includes, as sorters and line boys (Delivery boys). 


\section{Vehicle Dispatch and Vendor Supply}

By early morning 2.30 am onwards the vehicles start leaving the printing press and reach the depots or the drop points for the city editions. During this travelling period, the newspapers are only accompanied by the driver and a helper provided by the transport vendor. At the depot or the drop points, the driver and his helper perform the task of unloading the newspaper bundles. They are responsible to make sure that they transport the right no. of copies to the right depot or the drop point at the right time. Unloading at bigger depots are supervised by the sales executives, who join the depot at drop schedule time every morning. The executive makes sure that the vendor receives the correct number of copies. In case where there is a shortage, he is supposed to immediately fill the shortage by providing the vendors additional copies from the extra newspaper packets loaded in the vehicles at the press. If that is not sufficient he has to arrange to get the copies from the nearest depot or from the press directly.

The formation of depots or the drop points is entirely the vendor's prerogative to decide the site of his drop point in consultation with the company's circulation department. This is usually decided based on the no. of copies the vendor is ordering and the convenience to reach his service area.

The main newspaper sold at the depot is the city edition. It is sold in addition with special supplement by the salesman who charges the cover price with the main paper and its supplement. The cover price tends varies as its depends upon the day of the week because of the type of supplements supplied on that particular. During weekends, the cover price is mostly high because more pages in the supplements are issued on that day. This may be relevant to other days of the week also but usual depend upon the newspaper agency. The vendor's commission is $25 \%$ of the cover price. He has to manage all the expenses from commission, he earns and make profit from what he saves.

The delivery to home (reader) is done by the vendor early morning every day. The manner in which they perform distribution varies highly from vendor-to-vendor but their role in the supply chain can be generalized.

\section{Collection of Newspaper by Vendor}

A registered vendor gets his copies dropped at the designated drop point, whereas an unregistered vendor purchases his daily demand of copies from the depot agent directly in cash. They have to individually queue near the depot to get their copies as they are supposed to sign against the entry, which the agent maintains. Once the copies are purchased the vendor unbundles them to insert supplements inside the main paper. This work is done by both the vendor and his helpers (referred as
"Assorters" henceforth) collectively. The vendor is not a dedicated vendor to a particular newspaper, but also handles the distribution of other newspaper and magazines. For example, a newspaper vendor will be dealing in all the major newspaper publications like Times of India, The Indian Express, DNA, The Hindu etc. and other regional newspapers.

\section{Supplement Insertion and Line Preparation}

The vendor's team will be doing the supplement insertion for all the newspaper they are registered with or as per the demands of their respective clients. In case when a reader has also ordered a magazine then the vendor buys that as well from the concerned vendor on the day of their availability. All the newspapers are then segregated according to the demand of the reader. In the final step the drop lines are prepared in the sequence of dropping the newspaper by the line boy. For example a line may have 50 flats in an apartment. In this case a sequential line is prepared starting with flat 1, 2, $3 \ldots \ldots$ and so on with the no. of newspaper and magazines that reader has demanded. It may happen that the reader in flat 1 may demand only Newspaper A, reader in second flat may demand Newspaper A, Newspaper B and Newspaper C the third one may demand 5-10 titles of newspapers daily. In that case, their orders are prepared and inserted in the main cover and arranged sequentially to form a line. The flat no. is written on the main cover for the convenience of the line boys. The vendor and the as sorters referring to their client list do this activity. In most of the cases, this list is on their mental recall and they need not even refer the list. Then the line boys pick these lines and these line boys do the final drop at the readers place.

\section{Final Drop by the Line Boys/Delivery Boys}

The delivery boys do the final drop.

\section{Research Methodology}

In this study results are based on the case study method. The case study approach simplifies an improvement in the quality and quantity of data obtained from the industry (Gummesson, 1991) which helps the researcher to study and analyze the association and social practices that difficult to obtain using the quantitative approach (Miles et al., 1994).

For the study newspaper, circulation activity was chosen for making the decision. The selection of the activity was done for number of reasons. Firstly, this is the last mile delivery component of the newspaper supply chain. Secondly, high delays in circulation of the newspaper (it was observed that the last copy of the distribution was as late as 9 am) and increased 
complaints received by the newspaper company for delayed distribution. Thirdly, it involves not only the time dimensions but also other qualitative dimensions such as the motivation for the delivery boys, their salary component etc. and lastly, the newspaper circulation activity was completely performed by the independent vendors, not under the control of the newspaper company as the same vendor group were also performing the circulation activities for other newspaper companies.

Furthermore, interactions with the circulation managers reveals that the present last copy delivery timings in major areas were getting worse. It was understood that the newspaper reaches the reader at delayed time. This delay is considered to be having an impact on the readership as the reader now, has various options from where he can access the information (like TV News, Internet, Tablets, Smartphones etc.) and may push the readers to have less engagement with the newspaper and ultimately also affect his habit of reading newspaper. Hence, it is very important to have the newspaper at the readers place at the earliest possible time in the morning. The discussions mentioned that the ideal desired time of the newspaper by the readers is advancing. The reader wants to have the newspaper at the earliest time in the morning. Further, the management has an opinion that by achieving the same it will increase the readership and develop a habit of spending more time with the newspaper. In this study, the circulation activity is modeled with different on field scenarios with an objective of reducing the total delivery time of the Newspaper.

\section{The Company}

The study has been carried out at a leading Newspaper Publishing Company (NPC) located in the southern part of India. The NPC is characterized by its presence in every existing media platform-Newspapers, Magazines, Books, TV, Radio, Internet, Event Management, Outdoor Display, Music, Movies and more. The present distribution network of NPC in the selected city of study consists of the following Table 2 .

Table 2. Distribution network of NPC

\begin{tabular}{lr}
\hline Printing locations & 2 \\
Routes & 112 \\
Vehicles & 280 \\
Depots & 97 \\
Drop points & 323 \\
Regd. Vendors & 2761 \\
Sub Vendors (ex - Depot) & 4576 \\
Line boys & 25001 \\
Cash Stalls & 1892 \\
\hline
\end{tabular}

\begin{tabular}{ll} 
Table 3. Printing press capacity & \\
\hline Press & Capacity \\
\hline I & 150000 copies per hour \\
II & 150000 copies per hour \\
\hline
\end{tabular}

Table 4. Timeline of activities

\begin{tabular}{|c|c|c|c|}
\hline Activity details & Start Hrs.:Mins & Finish & Details of observations \\
\hline Vendor reporting time & $4.15 \mathrm{am}$ & - & Arrangement of the bundles \\
\hline Newspaper A (44 copies) & $4.25 \mathrm{am}$ & $4.26 \mathrm{am}$ & $\begin{array}{l}\text { i. Opening and adjustment (bundle) for supplement insertion } 10 \mathrm{sec} \text { ) } \\
\text { ii. Supplement Insertion (Avg. time- } 1.95 \mathrm{sec} / \text { supplement) } \\
\text { iii. Lifting and setting the bundles- } 22 \mathrm{sec} \\
\text { iv. Keeping away from siting place } \\
\text { Total time- } 117 \mathrm{sec} \text {. }\end{array}$ \\
\hline Newspaper B (90 copies) & $4.26 \mathrm{am}$ & $4.29 \mathrm{am}$ & $\begin{array}{l}\text { Opening and adjustment (bundle) for supplement insertion. } \\
\text { (Opening and adjustment-25 sec.) } \\
\text { Avg. time- } 1.66 \mathrm{sec} . / \text { supplement. } \\
\text { Lifting and setting the bundles- } 2.6 \mathrm{sec} \text {. } \\
\text { Total time- } 177 \mathrm{sec} \text {. }\end{array}$ \\
\hline Newspaper C (82 copies) & $4.30 \mathrm{am}$ & $4.33 \mathrm{am}$ & $\begin{array}{l}\text { Opening and adjustment (bundle) for supplement insertion } \\
\text { (Opening and adjustment-13 sec.) } \\
\text { Avg. time- } 2.09 \mathrm{sec} / \mathrm{supplement} \\
\text { Lifting and setting the bundles- } 9.42 \mathrm{sec} \text {. } \\
\text { Total time- } 193.8 \mathrm{sec} \text {. }\end{array}$ \\
\hline Newspaper D (70 copies) & $4.33 \mathrm{am}$ & $4.36 \mathrm{am}$ & $\begin{array}{l}\text { Opening and adjustment (bundle) for supplement insertion. } \\
\text { (Opening and adjustment-19 sec.) } \\
\text { Avg. time- } 1.95 \mathrm{sec} / \mathrm{supplement} \\
\text { Lifting and setting the bundles- } 8.3 \mathrm{sec} \text {. } \\
\text { Total time- } 163.8 \mathrm{sec} \text {. }\end{array}$ \\
\hline Newspaper E (06 copies) & 4.36.30 am & $4.36 .54 \mathrm{am}$ & Supplement insertion \\
\hline Newspaper F-A NPC & 4.38.01 am & $5.08 \mathrm{am}$ & Opening and adjust the 4 bundle for insertion + \\
\hline Publication ( 286 copies 2 & & & Again rearranging $(4 \times 40=160 \mathrm{sec})$. \\
\hline Supplements + 01 & & & Avg. time- $4.26 \mathrm{sec} /$ insertion $=1200 \mathrm{sec}$ \\
\hline wedding magazine) & & & Total $=30 \mathrm{~min}$ \\
\hline Line Boys reporting (No. & Line-boys) & Between 5.3 & $5.50 \mathrm{am}$ \\
\hline First copy drop & & $5.36 \mathrm{am}$ & \\
\hline Last copy drop & & $9.15 \mathrm{am}$ & \\
\hline
\end{tabular}


NPC has two printing facilities at the selected study location. Plant I is one of the oldest plants of NPC while the Plant II is the most modern in terms of printing and packaging operations. The printing operation is the most critical activity of the entire supply chain as this acts as the source of supply. The circulation or the distribution process is initiated once the newspaper is printed. The capacity details of the two printing press are given in Table 3 .

\section{The Problem}

A sample study was conducted covering the distribution of the newspaper from Plant 1 to one of the vendor located at a drop point in the city. The detailed timeline of activities is as shown in Table 4 . The newspaper consignment was dropped at the location at 4 am by the vehicle that had traveled from Plant 1 . The vendor had a total newspaper demand of 580, with a deployment of six line-boys and two assorting personnel for insertion of the supplements in the main cover.

It is to be observed from the above table that the main activity at the depot is assortment and supplement insertions. Once the supplement insertions are completed, the vendor calls the line boys for the final delivery. The arrival time of the delivery boys is not fixed. However, they start with the delivery of the newspaper as soon as they report. The last copy drop at the drop points depends on various factors such as number of line boys, mode of travel, type of service area (like apartment or independent house), distance from the drop point to the service are etc.

A discussion with the management revealed that they were concerned with the late last copy drop of the newspaper (at $9.15 \mathrm{am}$ ) and were of the opinion that the last copy drop should be completed within two hours of the first copy drop (i.e., by $7.40 \mathrm{am}$ ). The management requested for developing a model considering the various activities/scenarios between the first and the last copy drop.

The discussions were followed with a meeting with the vendors wherein the views of the management was shared with them for early deliveries. The vendors shared the following information:

i. Majority of the newspaper vendors performs the circulation as a part time employment. Most of them have secured jobs or other commitment during the day other than newspaper circulation. They perceive the newspaper circulation job as supplement to their incomes. It is because of this reason they do not want to expand their distribution chain and restrict themselves to necessary areas. Based on this it can be concluded that the vendors also wants to complete the circulation tasks as early as possible so that they are free to perform their other daily chores ii. It is observed that normally a line boy salary in big cities varies from INR Rs.1000-2000. It is also observed that in most of the cases the vendor, also joins the line boys for delivery and includes his family members to save this expenditure. This is applicable for the majority of vendors who are small players

iii. It was observed that even if the vendor and his assortment team complete the assortment/line laying/insertion, the line boys report at a scheduled time, which usually is after $5.30 \mathrm{am}$. It is observed that the vendor has to personally give mobile calls to wake up his line boys and in few cases go to their home to pick them up on scooters/motorbikes. One of the vendor said that he carries all his line boys in his car or pay for their auto fares

iv. There is always a shortage of attendance and approximately $70 \%$ of the line boys report for work every day. In absence of them, the vendor himself has to drop the lines. This also results in delays

v. However, the vendors felt that there is a need to have a model that can optimize the number of lineboys required for delivering the newspaper within the stipulated time of two hours from the time of start. This will help them to effectively plan the lineboy requirements. The next section deals with the various scenarios as observed in the field

\section{Model Formulation}

The process of distribution of newspapers from the drop point to the customer residence is modeled as an assignment problem with time windows and solved using genetic algorithm using MATLAB. The problem has been modeled as a single zone single vendor problem handling a constant customer demand of ' $Q$ ' newspapers every day with a maximum of ' $n$ ' line-boys. The vendor and the line-boys arrive at the hub at ' $T_{l}$ ' am everyday where the sorting and insertion processes are carried out. After this, at around ' $T_{\text {start }}$ ' am the line-boys carry the newspapers, travel to the customer residences and deliver the newspapers. The main objective of the problem is to calculate the number of papers to be allotted to any particular line-boy such that the distribution of the newspapers is achieved with minimum cost and before ' $T_{\text {end }}$ ' am (' $T$ ' hours from the start of the distribution process).

Parameters:

\section{$k \in(1,2,3, \ldots, n)$ denotes the line-boys}

Fixed salary of the line boys $=S a l_{k} /$ day

Delivery charge $=C_{d}$ / paper delivered

No. of papers delivered by Kth line boy, $d_{k}$

Travel and Maintenance cost $=C_{\text {travel }} /$ day

Start time of delivery of kth line boy, $T_{s k}$

Finish time of delivery of kth line boy, $T_{f k}$

Initial distance to community $=\mathrm{L} \mathrm{Kms}$ 
Velocity of cycle, $=v \mathrm{kmph}$

Service/delivery time $=T_{s} \mathrm{~h} /$ paper

Time taken to travel between 2 houses $=T_{t} \mathrm{~h}$

Objective function:

$$
\text { Minimize } \sum_{k=1}^{n} \mathrm{Sal} \mathrm{k}+\mathrm{Cd}(\mathrm{dk})+C \text { travel }
$$

Constraints:

$$
\begin{aligned}
& \sum d k=Q \\
& T_{s k}=T_{\text {start }} \\
& \mathrm{T}_{\mathrm{fk}} \leq \mathrm{T}_{\text {end }}
\end{aligned}
$$

Implies:

$$
T_{f k}=(L / v)+T_{s}\left(d_{k}\right)+T_{t}\left(d_{k}-l\right)+T_{s k} \leq T_{\text {end }}
$$

The data pertaining to this model was obtained from a study of the newspaper distribution process carried out by a distribution vendor at Mumbai in India. It was observed that the vendor was handling a constant customer demand of 1030 newspapers every day with a team of seven lineboys. The vendor and the lineboys arrived at the hub at 4 am everyday where the sorting and insertion processes were carried out. After this, at around 4:30 am the line boys carried the newspapers, travel to the customer houses and delivered the newspapers. The main objective of the problem is to calculate the number of papers to be allotted to a lineboy such that the distribution of the newspapers is achieved with minimum cost and before 6:30 am $(2 \mathrm{~h}$ from the start of the process).

Based on the type of houses of the customer and the mode of transportation mode used by the lineboys for travelling the problem can be classified as:

Case 1: Delivery to Independent Houses Located in a Community

This case is modeled on a vendor catering to independent house. The vendor is assumed to handle 1030 newspapers everyday with the help of seven lineboys who travel on a bicycle and deliver the newspapers. The customer houses are in the form of a community (cluster) having certain number of independent houses. The lineboys are required to travel an initial distance of four miles to reach the community, where they deliver the paper. Within the society the line boys takes $7 \mathrm{sec}$ to deliver the paper at one house (service time) and takes $45 \mathrm{sec}$ to travel from one independent house to another.

Assumptions:
- One house has a demand of only one newspaper

- Each lineboy serves different communities

- The lineboys are assumed to travel the initial distance to reach their respective community at a constant speed of $12 \mathrm{kmph}$

- The distance between any two houses are equal and constant

Parameters:

$k \in(1,2,3,4,5,6,7)$ denotes the lineboys

Fixed salary of the lineboys, $S a l_{k}=$ Rs 23/day

Delivery charge, $C_{d}=$ Rs $0.05 /$ paper delivered

No. of papers delivered by Kth line boy, $d_{k}$

Cycle Maintenance cost, $C_{c y l}=$ Rs 10/day

Start time of delivery of kth line boy, $T_{s k}$

Finish time of delivery of kth line boy, $T_{f k}$

Initial distance to community $\mathrm{L}=4 \mathrm{Kms}$

Velocity of cycle, $v=12 \mathrm{kmph}$

Service/delivery time, $T_{s}=0.00194 \mathrm{hrs} /$ paper

Time taken to travel between $2 \mathrm{~h}, T_{t}=0.0135 \mathrm{~h}$

Objective function:

$$
\text { Minimize } \sum_{k=1}^{7} \mathrm{Sal} \mathrm{k}+\mathrm{Cd}(\mathrm{dk})+C c y l
$$

Constraints:

$$
\begin{aligned}
\sum d k & =1030 \\
T_{s k} & =4.5 \\
T_{f k} & \leq 6.5
\end{aligned}
$$

Implies:

$$
T_{f k}=(L / v)+T_{s}\left(d_{k}\right)+T_{t}\left(d_{k}-1\right)+T_{s k} \leq 6.5
$$

This formulation was implemented and solved in Matlab 2011a optimization toolbox using genetic algorithm in its default stopping criteria. The result showed that the maximum demand that the vendor can cater in this scenario was 815 newspapers:

$\begin{array}{lllllll}\text { LB1 } & \text { LB2 } & \text { LB3 } & \text { LB4 } & \text { LB5 } & \text { LB6 } & \text { LB7 } \\ 116.244 & 116.203 & 116.583 & 116.58 & 116.58 & 116.244 & 116.566\end{array}$

However, in order to deliver 1030 papers within the given time window and with minimum cost, the vendor has to deploy two more lineboys in the distribution process. Looking at this model in a futuristic sense, suppose the demand of the community increases by $30 \%$, the new demand will be 1340 newspapers. This increased demand can be achieved within the time window, under the given constraints with the help of 12 line boys. 


\section{Case 2: Deliver to an Apartment Cluster}

This is model in which the customers are assumed to be living in apartments, which can be more closely related to the city of Mumbai. Each apartment is assumed to have $70 \mathrm{~h}$ i.e., 70 newspaper demands. The lineboys collect the paper after insertions and segregations from the drop off points or hub and together travel to an apartment in an auto-rickshaw. From here, the line boys split up and cover the entire demand of the locality, which is assumed 1050 newspaper or 15 apartments.

Assumptions:

- One house has a demand of only one newspaper and an apartment has 70 papers

- An apartment can be serviced by more than one lineboy

- The distance between any two apartments are equal and constant

- The lineboys together are assumed to travel the initial distance of $3 \mathrm{kms}$ to reach their respective apartment at a constant speed of $40 \mathrm{kmph}$

\section{Parameters:}

$k \in(1,2,3,4,5 .$.$) denotes the lineboys$

Fixed salary of the lineboys, $S_{a l}=$ Rs 23/day

Delivery charge, $C_{d}=$ Rs 3.5/apartment delivered

No. of apartments covered by Kth line boy, $A_{k}$

Travel cost, $C_{\text {auto }}=$ Rs 40/day

Start time of delivery of kth line boy, $T_{s k}$

Finish time of delivery of kth line boy, $T_{f k}$

Initial distance to community $\mathrm{L}=3 \mathrm{Kms}$

Velocity of cycle, $v=40 \mathrm{kmph}$

Service/delivery time, $T_{s}=0.33 \mathrm{hrs} /$ apartment

Time taken to travel between 2 apartments, $T_{t}=0.0833 \mathrm{~h}$

Objective function:

$$
\text { Minimize } \sum_{k=1}^{7} \mathrm{Sal} \mathrm{k}+\mathrm{Cd}(\mathrm{dk})+C \text { auto }
$$

Constraints:

$$
\begin{aligned}
& \sum A k=15 \\
& T_{s k}=4.5 \\
& T_{j k} \leq 6.5
\end{aligned}
$$

Implies:

$$
T_{f k}=(L / v)+T_{s}\left(A_{k}\right)+T_{t}\left(d_{k}-1\right)+T_{s k} \leq 6.5
$$

On solving, the above formulation in matlab optimization toolbox using genetic algorithm it was observed that the customer demand could be achieved with the help of just four line boys unlike the independent house system of case 1 . In addition, it was observed that a line boy can deliver a maximum of 4.65 apartments within the given time window in this scenario and hence altogether the 4 lineboys can serve a maximum of 18.73 apartments:

$\begin{array}{llll}\text { LB1 } & \text { LB2 } & \text { LB3 } & \text { LB4 } \\ 4.227 & 3.393 & 3.837 & 3.541\end{array}$

Suppose in future, if the demand for newspaper increases by say $30 \%$ the new demand will be 19.5 apartments. This new demand cannot be met by the four lineboys and hence another lineboy has to be deployed in the locality.

Case 3: Delivery Considering the Various Modes of Transportation

This model takes into consideration the various modes of transportation deployed in the distribution process. Let us assume that three modes of transportation say Mode 1, Mode 2, Mode 3 are deployed in the process. There exists ' $n$ ' lineboys in the system of which ' $p$ ' lineboys use Mode 1, 'q' lineboys use Mode 2, 'r' lineboys use Mode 3. This variation can only be implemented in case 1 i.e., the independent houses case and not the apartment model, because in the latter we have assumed that all the lineboys together travel in an auto-rickshaw to the first apartment and then split up to carry out the distribution process. In this model to increase the complexity, we introduce constraints on the quantity of the newspapers that can be carried by each mode of transportation say, $C_{1}, C_{2}$ and $C_{3}$. In addition, this model should be valid within the given time window and all other constraints followed by the model in case 1 .

Parameters:

$k \in(1,2,3, \ldots . n)$ denotes the lineboys

Fixed salary of the lineboys, $\mathrm{Sal}_{k}=\mathrm{Rs} 23$ day

Delivery charge, $C_{d}=$ Rs $0.05 /$ paper delivered

No. of papers delivered by Kth line boy using jth mode $=d_{k j}$ Travel cost of kth lineboy using jth mode $=C_{k j}$

Where $j \in(1,2,3)$ and $k \in(1,2,3, \ldots ., n)$

Capacity upper bound of mode $j=C_{j}$ newspapers

Start time of delivery of kth line boy, $T_{s k}$

Finish time of delivery of kth line boy, $T_{f k}$

Initial distances to respective communities $=L_{1}, L_{2}, L_{3}, \ldots$ ., $L_{n} \mathrm{Kms}$

Velocity of vehicle $=v_{1}, v_{2}, v_{3}, \ldots, v_{n} \mathrm{kmph}$

Service/delivery time $=T_{s} \mathrm{~h} /$ paper

Time taken to travel between 2 houses, $T_{1}, T_{2}, T_{3}, \ldots, T_{n} \mathrm{~h}$

Objective function: 


$$
\text { Minimize } \sum_{k=1}^{n} \mathrm{Sal} \mathrm{k}+\mathrm{Cd}(\mathrm{dk})+\sum C k j
$$

Constraints:

$$
\begin{aligned}
& \sum d k=Q \\
& T_{s k}=T_{\text {start }} \\
& T_{f k} \leq T_{\text {end }}
\end{aligned}
$$

Implies:

$$
T_{f k}=(L / v)+T_{s}\left(d_{k}\right)+T_{t}\left(d_{k}-1\right)+T_{s k} \leq T_{e n d} D_{k j} \leq C_{j}
$$

For demonstration let, we again take the model of a single vendor distribution model with a maximum of seven lineboys. Let us assume the three mode of transportations are bicycle, motorbikes and autorickshaws, which can be closely related to the Indian scenario. We assume that of the 7 lineboys 4 travel by cycle, 2 by motorbike and 1 by an auto rickshaw. Therefore, the lineboys will have a limit to the maximum capacity that they can carry which is 100 for a lineboy using cycle, 150 for a lineboy using motorbike and 500 for a lineboy using auto rickshaw. We also assume that for lineboys using different modes of transportation, the initial distances to be covered to reach the first house are different and the velocity with which they travel are different. Let us now look into the demonstration where lineboys 1, 2, 3 and 4 travel by bicycle, lineboys 5 and 6 travel by motorbike and lineboy 7 travels by auto rickshaw.

Assumptions:

- One house has a demand of only one newspaper

- Each lineboy serves different communities

- The lineboys are assumed to travel the initial distance to reach their respective community at a constant speed

- The distance between any two houses are constant and equal to $50 \mathrm{mtrs}$

Parameters:

$k \in(1,2,3,4,5,6,7)$ denotes the lineboys

Fixed salary of the lineboys, $S_{a l}=$ Rs 23/day

Delivery charge, $C_{d}=$ Rs $0.05 /$ paper delivered

No. of papers delivered by Kth line boy, $d_{k}$

Cycle Maintenance cost, $C_{c y l}=$ Rs 10/day

Travel cost for motorbike, $C_{m b}=\mathrm{Rs} 1.53 / \mathrm{Km}$

Travel cost for Auto rickshaw, $C_{\text {auto }}=\mathrm{Rs} 13 / \mathrm{Km}$

Start time of delivery of kth line boy, $T_{s k}$

Finish time of delivery of kth line boy, $T_{f k}$

Initial distance to community for lineboys using bicycle, $L_{c y c}=1.5 \mathrm{Kms}$

Initial distance to community for lineboys using bike, $L_{m b}=3 \mathrm{Kms}$
Initial distance to community for lineboys using auto, $L_{\text {auto }}=5 \mathrm{Kms}$

Velocity of cycle, $v=12 \mathrm{kmph}$

Velocity of motorbike, $v=35 \mathrm{kmph}$

Velocity of auto rickshaw, $\mathrm{v}=25 \mathrm{kmph}$

Service/delivery time, $T_{s}=0.00194 \mathrm{~h} /$ paper

Time taken to travel between 2 houses using bicycle, $T_{c y c}=0.004 \mathrm{~h}$

Time taken to travel between 2 houses using motorbike, $T_{m b}=0.0014 \mathrm{~h}$

Time taken to travel between 2 houses using autorickshaw, $T_{\text {auto }}=0.002 \mathrm{~h}$

Objective function:

$$
\begin{aligned}
& \text { Minimize } \sum_{k=1}^{4} \mathrm{Sal} \mathrm{k}+\mathrm{Cd}(\mathrm{dk})+C c y l+\sum_{k=5}^{6}(S a l k+C d(d k) \\
& +(L k+0.05(d k-1)) C m b+ \\
& \sum_{k=7}(S a l k+C d(d k)+(L k+0.05(d k-1)) C \text { auto }
\end{aligned}
$$

Constraints:

$$
\begin{aligned}
& \sum d k=1030 \\
& T_{s k}=4.5 \\
& T_{f k} \leq 6.5
\end{aligned}
$$

Implies:

$$
\begin{aligned}
T_{f k}=\left(L_{k} / v_{k}\right)+T_{s}\left(d_{k}\right)+T_{t k}\left(d_{k}-1\right) & +T_{s k} \leq 6.5 \\
& d_{1}, d_{2}, d_{3}, d_{4} \leq 100 \\
& d_{5}, d_{9} \leq 150 \\
& d_{7} \leq 6.5
\end{aligned}
$$

On solving this formulation in matlab 2011 optimization tool box for a demand of 1030 newspapers the solution we arrived at was:

$\begin{array}{lllllll}\text { C1 } & \text { C2 } & \text { C3 } & \text { C4 } & \text { B1 } & \text { B1 } & \text { A1 } \\ 100 & 100 & 100 & 100 & 150 & 150 & 330\end{array}$

In addition, it was observed that they were capable of delivering a demand of 1160 newspapers in the within the time window and the constraints. Suppose in future, if the demand of the locality increases say by $30 \%$, the new demand will be 1340 newspapers. This excess demand cannot be met with the existing lineboys and hence new lineboys have to be deployed in the process. This can be done in many ways, a few of which is illustrated below as solutions.

Introducing 2 new cyclists:

$\begin{array}{lllllllll}\mathrm{C} 1 & \mathrm{C} 2 & \mathrm{C} 3 & \mathrm{C} 4 & \mathrm{C} 5 & \mathrm{C} 6 & \mathrm{~B} 1 & \mathrm{~B} 2 & \mathrm{~A} 1 \\ 100 & 100 & 100 & 100 & 90 & 90 & 150 & 150 & 460\end{array}$


Introducing 1 new auto rickshaw:

$\begin{array}{llllllll}\text { C1 } & \text { C2 } & \text { C3 } & \text { C4 } & \text { B1 } & \text { B2 } & \text { A1 } & \text { A2 } \\ 100 & 100 & 100 & 100 & 150 & 150 & 460 & 180\end{array}$

Introducing 1 new cyclist and 1 new bike:

$\begin{array}{lllllllll}\mathrm{C} 1 & \mathrm{C} 2 & \mathrm{C} 3 & \mathrm{C} 4 & \mathrm{C} 5 & \mathrm{~B} 1 & \mathrm{~B} 2 & \mathrm{~B} 3 & \mathrm{~A} 1 \\ 100 & 100 & 100 & 100 & 100 & 80 & 150 & 150 & 460\end{array}$

Introducing 2 new bikes:

$\begin{array}{lllllllll}\mathrm{C} 1 & \mathrm{C} 2 & \mathrm{C} 3 & \mathrm{C} 4 & \mathrm{~B} 1 & \mathrm{~B} 2 & \mathrm{~B} 3 & \mathrm{~B} 4 & \mathrm{~A} 1 \\ 100 & 100 & 100 & 100 & 150 & 100 & 150 & 30 & 460\end{array}$

\section{Conclusion}

The results from the present study can save a newspaper's post-press production operations (i.e., distribution process) substantial time by improving the distribution process. This paper addresses a new extension using time window of utilizing the genetic algorithm by including new delivery boys/lineboy that have not been considered in the literature. It also consider three different scenarios as observed from the field i.e., delivery to independent houses, delivery to apartments and the mode of transportation mode used by the line boys for travelling to the distribution point. We have proposed an assignment problem with the time window and solved using genetic algorithm with matlab platform. The results from the different case situations presents a new formulation of the distribution process problem using genetic algorithm, as an objective of the optimization problem to adapt a distribution process with minimum cost.

\section{Acknowledgement}

Sincerely thanks to distribution channel of newspaper agency.

\section{Funding Information}

The authors have no support or funding to report.

\section{Authors Contribution}

Sachin Suresh Kamble: The proprietor of the study, he was principle investigator this study was carried under his supervision, formulation of problem, field visits, data collection, analysis, result generation etc.

Shradha Ashok Gawankar: Contributed in data collection and literature review.

Rakesh Raut: Accompanied during field visit and also helped in data collection.

\section{Ethics}

All ethical conducts are practiced and take care while conducting this study.

\section{References}

Akkerman, R., P. Farahani and M. Grunow, 2010. Quality, safety and sustainability in food distribution: A review of quantitative operations management approaches and challenges. OR Spectrum, 32: 863-904. DOI: 10.1007/s00291-010-0223-2

Archetti, C., K.F. Doerner and F. Tricoire, 2013. A heuristic algorithm for the free newspaper delivery problem. Eur. J. Operat. Res., 230: 245-257. DOI: 10.1016/j.ejor.2013.04.039

Bohnlein, D., C. Gahm and A. Tuma, 2009. A hybrid meta-heuristic for the VRPTW with clusterdependent tour starts in the newspaper industry. Proceedings of the 42nd Annual Hawaii International Conference on System Sciences, Jan. 5-8 IEEE Xplore Press, Big Island, HI, pp: 1-10. DOI: 10.1109/HICSS.2009.16

Beatrice, B.O. and F.T. Hanshar, 2009. Using genetic algorithms for multi-depot vehicle routing. Stud. Comput. Intell., 161: 77-99.

DOI: $10.1007 / 978-3-540-85152-34$

Burger, B., 2013. Optimizing delivery routes for newspapers and magazines using vehicle routing problem. University of Pretoria.

Böhnlein, D., K. Schweiger and A. Tuma, 2011. Multiagent-based transport planning in the newspaper industry. Int. J. Product. Econom., 131: 146-157. DOI: $10.1016 /$ j.ijpe.2010.04.006

Brown, E.C. and R.T. Sumichrast, 2005. Evaluating performance advantages of grouping genetic algorithms. Eng. Applic. Artificial Intell., 18: 1-12. DOI: 10.1016/j.engappai.2004.08.024

Buer Van, M.G., D.L. Woodruff and R.T. Olson, 1999. Solving the medium newspaper production/distribution problem. Eur. J. Operat. Res., 115: 237-253. DOI: $10.1016 / \mathrm{S} 0377-2217(98) 00300-2$

Cakici, E., S.J. Mason and M.E. Kurz, 2012. Multiobjective analysis of an integrated supply chain scheduling problem. Int. J. Product. Res., 50: 2624-2638. DOI: 10.1080/00207543.2011.578162

Carter, A.E. and C.T. Ragsdale, 2002. Scheduling preprinted newspaper advertising inserts using genetic algorithms. Omega, 30: 415-421. DOI: 10.1016/S0305-0483(02)00059-2

Chiang, W.C., R. Russell, X. Xu and D. Zeped, 2009. A simulation/metaheuristic approach to newspaper production and distribution supply chain problems. Int. J. Product. Econom., 121: 752-767.

DOI: 10.1016/j.ijpe.2009.03.001 
Das, M.M. and P.P. Sengupta, 2013. An analysis of the newspaper publishing industry-Can it survive the onslaught of the digital media. ZENITH Int. J. Bus. Econom. Manage. Res., 2: 114-130.

Dawande, M., H.N. Geismar and N.G. Hall, 2006. Supply chain scheduling: Distribution systems. Product. Operat. Manage., 15: 243-261. DOI: $10.1111 / \mathrm{j} .1937-5956.2006 . t b 00243 . \mathrm{x}$

Derbel, B., B. Jarboui, S. Hanafi and H. Chabchoub, 2012. Genetic algorithm with iterated local search for solving a location-routing problem. Expert Syst. Applic., 39: 2865-2871.

DOI: $10.1016 /$ j.eswa.2011.08.146

Dethloff, J., 2001. Vehicle routing and reverse logistics: The vehicle routing problem with simultaneous delivery and pick-up. OR-Spektrum, 23: 79-96. DOI: 10.1007/PL00013346

Dethloff, J., 2002. Relation between vehicle routing problems: An insertion heuristic for the vehicle routing problem with simultaneous delivery and pick-up applied to the vehicle routing problem with backhauls. J. Operat. Res. Society, 53: 115-118. DOI: $10.1057 /$ palgrave.jors.2601263

Ehmke, J.F., A.M. Campbell and T.L. Urban, 2015. Ensuring service levels in routing problems with time windows and stochastic travel times. Eur. J. Operat. Res., 240: 539-550. DOI: 10.1016/j.ejor.2014.06.045

Garcia, M.L., M.A. Centeno and G. Peñaloza, 1999. A simulation of the product distribution in the newspaper industry. Proceedings of the Winter Simulation Conference, Dec. 5-8, IEEE Xplore Press, pp: 1268-1271. DOI: 10.1109/WSC.1999.816852

Geismar, H.N., M. Dawande and C. Sriskandarajah, 2011. Pool-point distribution of zero-inventory products. Product. Operat. Manage., 20: 737-753. DOI: $10.1111 /$ j.1937-5956.2010.01190.x

Geismar, H.N., G. Laporte, L. Lei and C. Sriskandarajah, 2008. The integrated production and transportation scheduling problem for a product with a short lifespan. J. Comput., 20: 21-33. DOI: 10.1287/ijoc.1060.0208

Gendreau, M., F. Guertin, J.Y. Potvin and E. Taillard, 1999. Parallel tabu search for real-time vehicle routing and dispatching. Trans. Sci., 33: 381-390. DOI: $10.1287 /$ trsc.33.4.381

Gribkovskaia, I., G. Laporte and A. Shyshou, 2008. The single vehicle routing problem with deliveries and selective pickups. J. Comput. Operat. Res., 35: 2908-2924. DOI: 10.1016/j.cor.2007.01.007

Gummesson, E., 1991. Qualitative Methods in Management Research. 2nd Edn., SAGE Publications, Thousand Oaks, ISBN-10: 1452251894, pp: 264.

Halskausr, O., I. Gribkovskaia, M. Vlcek and G. Laporte, 2007. General solutions to the single vehicle routing problem with pickups and deliveries. Eur. J. Operat. Res., 180: 568-584.

DOI: $10.1016 /$ j.ejor.2006.05.009
Hernández-Pérez, H. and J.J. Salazar-González, 2009. The multi-commodity one-to-one pickup-and-delivery traveling salesman problem. Eur. J. Operat. Res., 196: 987-995. DOI: 10.1016/j.ejor.2008.05.009

Hoff, A., I. Gribkovskaia, G. Laporte and A. Løkketangen, 2009. Lasso solution strategies for the vehicle routing problem with pickups and deliveries. Eur. J. Operat. Res., 192: 755-766. DOI: 10.1016/j.ejor.2007.10.021

Huo, Y., Y.T. Leung and X. Wang, 2010. Integrated production and delivery scheduling with disjoint windows. Discrete Applied Math., 158: 921-931. DOI: 10.1016/j.dam.2009.12.010

Kumar, S. and V.V.S. Sarma, 2015. Performance and challenges of newspapers in India: A case study on English versus vernacular dailies in India. Proceedings of the 12th AIMS International Conference on Management, (ICM' 15), pp: 901-912.

Lei, L., S. Liu, A. Ruszczynski and S. Park, 2006. On the integrated production, inventory and distribution routing problem. IIE Trans., 38: 955-970. DOI: $10.1080 / 07408170600862688$

Min, H., 1989. The multiple vehicle routing problem with simultaneous delivery and pick-up points. Trans. Res. Part A, 5: 377-386. DOI: 10.1016/0191-2607(89)90085-X

Miles, M.B., A. Michael, M.H. Huberman and J. Saldaña, 1994. Qualitative Data Analysis: An Expanded Sourcebook. 1st Edn., SAGE, Thousand Oaks, ISBN-10: 0803955405, pp: 338.

Montane, F.A.T. and R.D. Galvao, 2002. Vehicle routing problems with simultaneous pick-up and delivery service. Opserach, 39: 19-33.

Montane, F.A.T. and R.D. Galvao, 2006. A tabu search algorithm for the vehicle routing problem with simultaneous pick-up and delivery service. Comput. Operat. Res., 33: 595-619.

DOI: $10.1016 /$ j.cor.2004.07.009

Mosheiov, G., 1994. The travelling salesman problem with pick-up and delivery. Eur. J. Operat. Res., 79: 299-310. DOI: 10.1016/0377-2217(94)90360-3

Narasimhan, M.S. and L.V. Ramana, 1995. Pricing of initial public offerings: Indian experience with equity issues. ICFAI J. Applied Finance, 1: 26-39.

Nagy, G. and S. Salhi, 1998. The many-to-many location-routing problem. TOP, 6: 261-275. DOI: $10.1007 / \mathrm{BF} 02564791$

Nagy, G. and S. Salhi, 2005. Heuristic algorithms for single and multiple depot vehicle routing problems with pickups and deliveries. Eur. J. Operat. Res., 162: 126-141. DOI: 10.1016/j.ejor.2002.11.003

Nguyen, P.K., T.G. Crainic and M. Toulouse, 2014. A hybrid generational genetic algorithm for the periodic vehicle routing problem with time windows. J. Heurist., 20: 383-416. DOI: $10.1007 / \mathrm{s} 10732-014-9244-3$ 
Rajmohan, M. and P. Shahabudeen, 2008. Genetic algorithm based approach for vehicle routing problem with time windows. Int. J. Logist. Syst. Manage., 4: 338-365. DOI: 10.1504/IJLSM.2008.017480

Russell, R., 2013. A constraint programming approach to designing a newspaper distribution system. Int. J. Product. Econom., 145: 132-138. DOI: $10.1016 /$ j.ijpe.2013.01.018

Russell, R., W.C. Chiang and D. Zepeda, 2008. Integrating multi-product production and distribution in newspaper logistics. Comput. Operat. Res., 35: 1576-1588.

DOI: $10.1016 /$ j.cor.2006.09.002

Salhi, S. and G. Nagy, 1999. A cluster insertion heuristic for single and multiple depot vehicle routing problems with backhauling. J. Operat. Res. Society, 50: 1034-1042. DOI: 10.1057/palgrave.jors.2600808

Sivaramkumar, V., M.R. Thansekhar, R. Saravanan and S.M.J. Amali, 2015. Multi-objective vehicle routing problem with time windows: Improving customer satisfaction by considering gap time. J. Eng. Manufacture. DOI: 10.1177/0954405415586608

Srivastava, B. and A. Srivastava, 2015. Electronic versus print newspaper: An Indian readers approach. BVIMR Manage. Edge, 8: 57-65.

Süral, H. and J.H. Bookbinder, 2003. The single-vehicle routing problem with unrestricted backhauls. Networks, 41: 127-136. DOI: 10.1002/net.10067

Sutar, D.B., 2007. History of newspapers. SRELS J. Inform. Manage., 44: 83-94.

Ting, C.K. and X.L. Liao, 2013. The selective pickup and delivery problem: Formulation and a memetic algorithm. Int. J. Product. Econom., 141: 199-211. DOI: 10.1016/j.ijpe.2012.06.009
Ullrich, C.A., 2011. Multi-agent-based transport planning in the newspaper industry. Int. J. Product. Econom., 131: 146-157. DOI: $10.1016 /$ j.ijpe.2010.04.006

Vidal, T., T.G. Crainic and M.G.C. Prins, 2013. A hybrid genetic algorithm with adaptive diversity management for a large class of vehicle routing problems with time-windows. Comput. Operat. Res., 40: 475-489. DOI: 10.1016/j.cor.2012.07.018

Wallace, A., 2012. Newspaper distribution as vehicle routing problem. Institute of Distance Learning, Kwame Nkrumah University of Science and Technology.

Wang, H.F. and Y.Y. Chen, 2013. A coevolutionary algorithm for the flexible delivery and pickup problem with time windows. Int. J. Product. Econom., 141: 4-13. DOI: 10.1016/j.ijpe.2012.04.011

Wasner, M. and G. Zäphel, 2004. An integrated multidepot hub-location vehicle routing model for network planning of parcel service. Int. J. Product. Econom., 90: 403-419. DOI: 10.1016/j.ijpe.2003.12.002

Wassan, N.A. and G. Nagy, 2014. Vehicle routing problem with deliveries and pickups: Modelling issues and meta-heuristics solution approaches. Int. J. Trans., 2: 95-110. DOI: 10.14257/ijt.2014.2.1.06

Yu, J. and Y. Dong, 2013. Maximizing profit for vehicle routing under time and weight constraints. Int. J. Product. Econom., 145: 573-583. DOI: 10.1016/j.ijpe.2013.05.009 